\title{
Fundamentos teórico-conceituais aplicáveis à revisão e à atualização de tesauros
}

\author{
Theoretical and conceptual frameworks applicable to reviewing and updating thesaurus
}

\author{
Ana Carolina Ferreira \\ Doutoranda em Gestão e Organização do Conhecimento \\ Universidade Federal de Minas Gerais \\ anacarolinaf2004c@gmail.com \\ Benildes Coura Moreira dos Santos Maculan \\ Doutora em Ciência da Informação \\ Universidade Federal de Minas Gerais \\ benildes@gmail.com
}

\begin{abstract}
Resumo
O artigo situa-se no escopo mais amplo de uma pesquisa de doutorado, caracterizada como qualitativa, exploratória, pragmática, aplicada, com respaldo na estratégia metodológica da pesquisa-ação, tendo como proposta desenvolver uma metodologia de revisão e atualização de tesauros. Nesse contexto, este trabalho objetiva oferecer contribuições ao modelizador de tesauros e à pesquisa em Biblioteconomia e Ciência da Informação sobre os principais aspectos teóricos aplicáveis à revisão e à atualização de tesauros. Para tanto, contextualiza, a partir da metodologia de revisão narrativa, os contributos teóricos dos principais domínios do conhecimento que fazem interface com a temática pesquisada, a saber: Biblioteconomia, Ciência da Informação), Terminologia e Linguística. Sob esse enfoque, destaca os princípios da Teoria da Classificação Facetada (TCF), de Ranganathan, e da Teoria do Conceito, de Dahlberg. Os aportes teóricos de Dahlberg para a compreensão das características dos conceitos são utilizados na elaboração de definições mais consistentes, as quais são a base para o processo de modelagem conceitual em tesauros, em especial para a criação de relações semânticas. Os aspectos teóricos da Linguística sobre a semântica e a criação de campos semânticos em tesauros também são destacados. Expõem-se, também, as recomendações da norma internacional ISO 25.964-1 (2011) sobre os critérios para elaborar-se relações semânticas hierárquicas, associativas e de equivalência em tesauros. Evidencia-se a aplicabilidade dos princípios teóricos na pesquisa empírica referente à modelagem conceitual de um protótipo de tesauro. As considerações finais revelam a importância dos aportes teóricos para a construção de definições na modelagem conceitual de tesauros.
\end{abstract}

\section{Palavras-chave}

Definições em tesauros. Relações semânticas. Semântica. Teoria da Classificação Facetada. Teoria do Conceito. Tesauro.

\begin{abstract}
The article is part of a broader doctoral research, which is characterized as a qualitative, exploratory, pragmatic, applied study, and supported by the methodological strategy of action research, with the proposal to develop a methodology for reviewing and updating thesauri. In this context, the aim of the present study was to help those who develop thesaurus and contribute to research in Librarianship and Information Science (IS) regarding the main theoretical aspects applicable to reviewing and updating thesauri. Therefore, based on the narrative review methodology, we contextualize the theoretical contributions of the main domains of knowledge that are associated with the area investigated, namely: Librarianship, Information Science (IS), Terminology and Linguistics. The principles of Ranganathan's theory of faceted classification (FC) and Dahlberg's concept theory will be discussed. Dahlberg's theoretical contributions to the understanding of the characteristics of concepts are used
\end{abstract}

DOI: $10.28998 /$ cirev.2020v7n1d

Submetido em: 05/04/2020

Aceito em: $25 / 04 / 2020$

Este artigo está licenciado sob uma Licença Creative Commons 4.0

Publicado em: 15/05/2020 
to build more consistent definitions, which are the framework for the process of conceptual modeling of thesaurus, particularly for the development of semantic relationships. The theoretical aspects of Linguistics on semantics and the development of semantic fields in thesaurus are also addressed. The recommendations of the international standard ISO 25.964-1 (2011) regarding the criteria for developing hierarchical, associative and equivalent semantic relationships in thesauri are discussed. The applicability of the theoretical principles for empirical research concerning the conceptual modeling of a thesaurus prototype will also be addressed. The final considerations reveal the importance of the theoretical contributions for the development of definitions for the conceptual modeling of thesaurus.

\section{Keywords}

Thesaurus definitions. Semantic relationships. Semantics. Theory of Faceted Classification. Concept Theory. Thesaurus.

\section{INTRODUÇÃO}

Os tesauros constituem instrumentos mediadores da comunicação da informação em sistemas de recuperação da informação (SRIs), realizando a compatibilização de distintas terminologias utilizadas por produtores, utilizadores e organizadores da informação. Como instrumentos de representação da linguagem, estão sujeitos a constantes mudanças, decorrentes da evolução do conhecimento e, portanto, da terminologia que os representa.

Diante do fato de que a mudança na linguagem tem impactos diretos na terminologia dos tesauros, identificou-se a necessidade de buscar-se, nas literaturas de Biblioteconomia, Ciência da Informação, Terminologia e Linguística, os princípios teóricos e normativos que subsidiam os processos de revisão e atualização de tesauros. Destaca-se que parte do conteúdo apresentado neste artigo integra o capítulo do referencial teórico de uma pesquisa de doutorado, que trata do desenvolvimento de procedimentos metodológicos para a revisão e atualização de tesauros, sendo caracterizada como qualitativa, exploratória, pragmática e aplicada, com a adoção da estratégia metodológica da pesquisa-ação. A referida pesquisa está sendo desenvolvida no âmbito do Programa de Pós-Graduação em Gestão e Organização do Conhecimento, da Escola de Ciência da Informação da Universidade Federal de Minas Gerais (PPGGOC/ECI/UFMG).

Tendo como norte a pesquisa mais ampla, empreenderam-se esforços para construir um arcabouço teórico fundamental para subsidiar o desenvolvimento de tesauros. Sem a intenção de esgotar o tema, caracteristicamente complexo e multidisciplinar, este artigo objetiva compilar parte desses fundamentos teóricos e oferecer ao modelizador ${ }^{1}$ de tesauros e à pesquisa em Ciência da Informação os principais contributos teóricos para o processo de revisão e atualização de tesauros.

Como metodologia adotada, empregou-se a revisão narrativa, que é, em geral, adequada ao mapeamento do estado da arte sobre um dado assunto, sob o propósito de explorar a literatura, pois a pesquisa exploratória permite familiarizar-se com um assunto ainda pouco explorado na literatura (GIL, 2008), tal qual o é a temática da revisão e atualização de tesauros. A revisão narrativa é conhecida como uma revisão tradicional, quando a busca e seleção de referências não têm por base critérios rígidos e explícitos de inclusão e exclusão

\footnotetext{
${ }^{1}$ Profissional que lida com a modelagem conceitual de tesauros ou de outros Sistemas de Organização do Conhecimento ( $\mathrm{SOC}$ ), como taxonomias, sistemas de classificação e ontologias. A modelagem é entendida, neste artigo, como o processo de se criar a estrutura conceitual de um instrumento terminológico, por meio das seguintes atividades: elaboração de definições, preenchimento de fichas terminológicas, formação e agrupamento de conceitos, levantamento de classes básicas, facetas e subfacetas, organização do sistema conceitual e criação de relações semânticas.
} 
de documentos (ROTHER, 2007), e não tem como propósito esgotar as fontes de informação (CORDEIRO et al., 2007). Sendo assim, as fontes não foram predeterminadas, a seleção foi feita de maneira arbitrária, e a inclusão de documentos ocorreu a partir de uma análise crítica da literatura publicada, quando foram definidos quais conteúdos foram mais relevantes para o escopo da pesquisa.

Seguindo esses princípios, a coleta e a análise do material foram realizadas no período de janeiro a dezembro de 2019, e a busca por documentos não se restringiu a um período temporal específico. A fonte inicial de busca de informações foi o Catálogo Bibliográfico da Rede de Bibliotecas da UFMG (Pergamum), e as bibliografias elencadas nos programas de disciplinas sobre construção de linguagens documentárias e de indexação, de duas importantes instituições de ensino de Biblioteconomia no Brasil: da UFMG e da Universidade de São Paulo (USP). A escolha dos programas desses dois cursos se deu de forma arbitrária, dada a proximidade da proponente com pesquisadores das duas instituições. O uso das bibliografias indicadas nos programas das disciplinas mencionadas se justifica pelo significado atribuído por Japiassu (1976, p. 61) quando afirma que "O domínio material das disciplinas [...] [é representado pelo] ângulo específico sob o qual a disciplina considera seu domínio material [...] [juntamente com a] integração teórica dos conceitos fundamentais"; com isso, acredita-se que os programas das disciplinas são "[...] capazes de abranger todos os fenômenos próprios, [...] os métodos próprios [...] [e] os instrumentos de análise [...] na construção de modelos; [...] [que] se revelam em sua concepção epistemológica [...]"; razão pela qual é possível escrutinar uma visão histórica do conteúdo da disciplina, que "retomam e ampliam os quatro [processos] propostos por Piaget: 'domínio material', 'domínio conceitual', 'domínio epistemológico interno' e 'domínio epistemológico derivado'”. Também nessa fase inicial foram consultados materiais de acervo pessoal e, depois, aqueles indicados por especialistas na temática.

De maneira geral, os critérios de inclusão e exclusão incluíram selecionar: 1) documentos que tratavam especificamente do assunto pesquisado e 2) documentos e autores recorrentemente citados na literatura recuperada, que foram considerados autores seminais sobre a temática pesquisada.

Todos os documentos recuperados foram lidos e analisados de maneira crítica, tendo sido verificado que os autores seminais abarcam pesquisadores, como Shiyali Ramamrita Ranganathan (Teoria da Classificação Facetada - TCF), Ingetraud Dahlberg (Teoria do Conceito), John Lyons (Linguística), Eugen Wüster (Terminologia), Bernard Pottier (Semântica), Charles J. Fillmore (Semântica) e Jean Claude Gardin (Semântica). Foi constatado que os fundamentos do escopo da pesquisa perpassam pelos princípios da TCF, da Teoria do Conceito, pelos aportes para a elaboração de definições, tanto da Ciência da Informação quanto da Terminologia, pelos aspectos da semântica linguística e das relações conceituais nos tesauros. Tais conteúdos, nessa ordem, são utilizados como seções que organizam a estrutura inicial deste artigo, após esta breve introdução. A seguir, também são apresentadas as principais contribuições do referencial teórico para o desenvolvimento da pesquisa empírica, finalizando com as considerações finais.

\section{FUNDAMENTOS TEÓRICO-CONCEITUAIS APLICÁVEIS À REVISÃO E À ATUALIZAÇÃO DE TESAUROS}

A revisão e a atualização de tesauros são procedimentos complexos em relação ao desenvolvimento de tesauros. Neste artigo, entende-se que o conceito de "revisão" se aplica 
aos tesauros que demandem reformulações de sua estrutura conceitual, decorrentes de mudanças substanciais na terminologia, a exemplo de uma mudança conceitual no domínio. Ao realizar-se a revisão de um tesauro, estão implicados, simultaneamente, procedimentos de "atualização", entendidos como inserção, modificação, exclusão de termos e de registros em bases de dados indexadas, por exemplo. Para realizar-se tais procedimentos, é fundamental a adoção de diretrizes científicas e normativas que respaldem o processo de modelização e/ou reestruturação conceitual de tais instrumentos terminológicos.

Nesse contexto, para o planejamento da estrutura conceitual, criação de categorias, classes, subclasses, definições e relações semânticas em tesauros, destacam-se: a TCF, a Teoria do Conceito, os aportes teóricos da Ciência da Informação e da Terminologia para a elaboração de definições, os construtos teóricos da Linguística sobre a semântica e os critérios normativos aplicáveis à construção de relações conceituais, incluindo recomendações da norma internacional International Standard Organization (ISO) 25.964-1 (ISO, 2011), conforme apresentado a seguir.

\subsection{Princípios da Teoria da Classificação Facetada (TCF)}

A TCF compreende o conjunto de princípios, cânones e postulados apresentados nas publicações de Ranganathan e do Classification Research Group (CRG), e que constituem subsídios para se organizar estruturas conceituais de forma mais consistente. Esses princípios se aplicam a diversos tipos de Sistemas de Organização do Conhecimento (SOC), como os sistemas de classificação, taxonomias e, em especial, os tesauros.

Um dos princípios mais importantes no pensamento ranganathiano refere-se à abordagem analítico-sintética, que permite decompor um assunto em suas partes componentes, investigar e entender a sua estrutura, para, posteriormente, recompô-la por meio da síntese dos seus aspectos mais importantes. Nessa abordagem, há infinitas possibilidades de interligar-se conceitos de diversos modos. Isso corrobora para que, "Do ponto de vista metodológico, os instrumentos de base analítico-sintéticos [possam oferecer] maiores possibilidades de descrição e recuperação de conteúdos multidimensionais exigidas pelos Sistemas de Recuperação da Informação." (CAFÉ; BRATFISCH, 2007, p. 238).

O conceito de faceta, em Ranganathan (1967), também é elemento de destaque, e indica a aplicação de um princípio de divisão para se organizar uma estrutura conceitual. Para Ranganathan (1967, p. 88), a faceta é "[...] um termo genérico, [que é] utilizado para denotar qualquer componente - pode ser um assunto básico ou um isolado - de um assunto composto [...]". Essa concepção é especialmente útil na organização de classes e subclasses nos tesauros.

Como subsídio à modelagem conceitual e ao planejamento da estrutura conceitual dos tesauros, Ranganathan (1967) vislumbrou três tipos de cânones: o plano ideacional, o plano verbal e o plano notacional, os quais estão presentes na organização da obra Prolegomena. Assim, o plano das ideias é a esfera na qual ocorre o processo de pensar e onde se originam as ideias, que são concretizadas nas instâncias verbal e notacional. O plano verbal relaciona-se ao desenvolvimento da linguagem como meio de comunicação, permitindo que ela "possa ser uma mediadora para a comunicação de ideias ou conceitos, [devendo, para tanto] ser livre de homonímia e sinonímia" (CAMPOS, 2001, p. 46). Já o plano notacional, no contexto da classificação, é o plano dos símbolos, que codifica os conceitos, e cuja função é conferir maior precisão à linguagem, a qual, nessa situação, se torna livre de homônimos e sinônimos (CAMPOS, 2001). 
Correlacionando esse raciocínio ao contexto dos tesauros, em primeiro lugar, vem a concepção do sistema conceitual, no planejamento e pensamento, o que corresponde ao plano das ideias; posteriormente, as ideias podem ser verbalizadas e comunicadas para outros, gerando, por sua vez, novas ideias. É no plano notacional, porém, que toda a concepção do sistema classificatório se concretiza, por meio de uma linguagem normalizada, que são os símbolos ou termos (GOMES; MOTTA; CAMPOS, 2006). Na elaboração de tesauros, são importantes os cânones "[...] do plano das ideias, ou seja, os princípios para organização das classes, das subclasses e dos elementos no interior destas, a saber das [estruturas conceituais na forma de] cadeias e renques." (GOMES; MOTTA; CAMPOS, 2006, on-line).

Outro contributo de Ranganathan (1967) para a revisão e atualização de tesauros se refere às cinco categorias fundamentais - Personalidade, Matéria, Energia, Espaço e Tempo (PMEST). Elas possibilitam ao modelizador pensar nos metaníveis conceituais para a organização conceitual e, assim, definir as classes básicas que refletem objetos materiais e imateriais, atributos, processos, espaço e tempo. As categorias fundamentais situam-se, dessa forma, nos níveis mais abrangentes de ideias da classificação e permitem, desse modo, criar as classes básicas dos tesauros, que, por sua vez, representam manifestações das categorias fundamentais. Por outro lado, as categorias fornecem a visão dos agrupamentos que ocorrem na estrutura conceitual, possibilitando, assim, o entendimento global da área (CAMPOS, 2001). A título exemplificativo, têm-se as seguintes possibilidades de aplicação das categorias PMEST na organização conceitual do recorte temático referente à Contabilidade Patrimonial ${ }^{2}$, situada no domínio da Contabilidade Pública: Personalidades (objetos) - ativo, passivo, patrimônio líquido; Matéria (atributos) - regime de caixa, regime de competência; Energia (processos) - amortização, depreciação, exaustão, mensuração; Espaço - não se aplica; Tempo - exercício financeiro, que corresponde ao período de doze meses ou ao ano civil.

Observa-se que as cinco categorias fundamentais (PMEST) podem ser percebidas nas facetas, que, por sua vez, constituem ocorrências dentro das categorias. Ranganathan (1967) destaca que uma mesma ideia isolada pode ser considerada uma manifestação da categoria fundamental Personalidade em um assunto e como Matéria em outro assunto. Por exemplo, no assunto básico Agricultura, a ideia isolada fibra de algodão é uma manifestação da categoria Personalidade. Mas no assunto básico Tecnologia têxtil, a ideia isolada fibra de algodão é uma manifestação da categoria Matéria. Em outro exemplo, a ideia isolada minério de ferro é Personalidade dentro do assunto básico mineração e Matéria dentro do assunto básico metalurgia. As diferentes maneiras de modelização dependem do contexto do assunto analisado (RANGANATHAN, 1967).

Ranganathan (1967) também fornece à literatura aplicável ao desenvolvimento de tesauros os princípios para a formação dos assuntos, os quais ocorrem, dinamicamente, pelos processos de aglutinação e de associação, acompanhando o desenvolvimento do conhecimento. $\mathrm{O}$ universo do conhecimento corresponde à "[...] soma total, num dado momento, do conhecimento acumulado, [que] está sempre em desenvolvimento contínuo." (RANGANATHAN, 1963, p. 359). O movimento do conhecimento é cíclico e em espiral, refletindo os estágios da investigação científica, que normalmente se inicia a partir da percepção de um problema. A compreensão de como os assuntos são formados auxilia o modelizador no processo de organização temática da informação, tanto na análise dos documentos quanto na indexação de assuntos e também na recuperação dos conteúdos em bases de dados. Os princípios para a formação dos assuntos são úteis, ainda, na criação de termos coordenados

\footnotetext{
${ }^{2}$ Recorte temático com o qual se trabalhou na pesquisa empírica.
} 
ou pós-coordenados nos tesauros, a partir da análise das características dos conceitos que se deseja representar.

Assim, para a revisão, atualização e organização da estrutura conceitual dos tesauros da TCF (RANGANATHAN, 1963, 1967), são essenciais os elementos da abordagem analíticosintética, das facetas, das cinco categorias PMEST, dos planos de trabalho e dos modos de formação dos assuntos. Esses princípios teóricos são especialmente úteis quando aplicados em conjunto com os fundamentos da Teoria do Conceito, que está abordada na próxima seção.

\subsection{Teoria do Conceito}

Na revisão e atualização de tesauros, a Teoria do Conceito, desenvolvida por Dahl$\operatorname{berg}^{3}$ (1978a, b, c, d, 1992, 2006, 2009, 2014a, b), possibilita entender as características dos conceitos, e, assim, obter suporte para a criação de definições e relações semânticas. Na elaboração de sua teoria, a autora incorporou os princípios analítico-sintéticos de Ranganathan (1967), pois, de acordo com essa concepção, os conceitos são decompostos a partir do estudo de suas características, que são, posteriormente, sintetizadas para criar estruturas conceituais e relações semânticas.

Em Dahlberg, o conceito é uma unidade de conhecimento, formada por elementos de conhecimento, que são as características dos conceitos (GOMES; CAMPOS, 2019). Sob esse ponto de vista, Dahlberg $(1978 \mathrm{a}, \mathrm{c})$ defende que o conceito é a unidade básica para a representação do conhecimento contido nos documentos, sendo definido como a "[...] compilação de enunciados verdadeiros sobre determinado objeto [item de referência] [...], fixada por um símbolo linguístico, [que] [...] pode ser verbal ou não verbal." (DAHLBERG, 1978d, p. 102). Para a autora, "Cada afirmação verdadeira sobre um determinado item de referência fornece um elemento de conhecimento sobre o objeto, junto com uma característica de seu conceito." (DAHLBERG, 2009, p. 171). A partir da reunião desses elementos de conhecimento, é possível formar sistemas de organização do conhecimento, cujos elementos básicos são os próprios conceitos.

Segundo Dahlberg (1992), o conceito é concebido a partir de um conjunto de predicações sobre o objeto (material ou imaterial), também denominado referente, que é o centro de sua teoria (GOMES; CAMPOS, 2019). A soma total das predicações compõe a totalidade das características desse conceito, segundo os parâmetros definidos para a representação. O modelo de Dahlberg (1992) para a construção do conceito e fixação do termo obedece a um certo fluxo de pensamento, no qual se verificam três elementos: a) aspecto referencial; b) aspecto predicacional; e c) aspecto representacional (CAMPOS, 2001), conforme sintetizado na Figura 1.

Observa-se, pela análise da Figura 1, que a formação do conceito parte de um universo de objetos (ideias, fatos ou situações) para o qual há um correspondente elemento de referência (A). Tendo esse elemento de referência como escopo, afirmações verdadeiras (B) são feitas sobre ele, com a finalidade de caracterizá-lo, e, posteriormente, ocorre a síntese

\footnotetext{
${ }^{3}$ Embora outros autores da Ciência da Informação tenham discutido sobre o conceito, como Campos e Gomes (2004), Hjørland (2008, 2009), Melo e Bräscher (2014), Barité (2015) e Maculan (2015), escolheu-se por priorizar os estudos teóricos de Dahlberg, que é considerada autora seminal sobre essa temática na área. Além disso, seus princípios teóricos continuam atuais em relação à aplicabilidade no desenvolvimento da modelagem conceitual em tesauros, com resultados satisfatórios em relação à elaboração de definições e relações conceituais para os termos. Essa assertiva pôde ser confirmada durante a pesquisa empírica, cuja modelagem conceitual vem sendo respaldada nesses princípios teóricos.
} 
das afirmações verdadeiras sobre o item em uma forma verbal ou nome, que é o termo (C), cuja função é comunicativa. Finalmente, ocorre o uso e a aplicação dessa forma verbal em instrumentos terminológicos, por exemplo. Embora o processo não seja linear e processual, como mostrado na Figura 1, há a síntese dos elementos presentes na construção do conceito, segundo a concepção de Dahlberg (1978a, b, d, 1992). Assim, há, em sua teoria, a aplicação dos princípios analítico-sintéticos de Ranganathan (1967).

Figura 1 - Modelo de Dahlberg para a construção do conceito

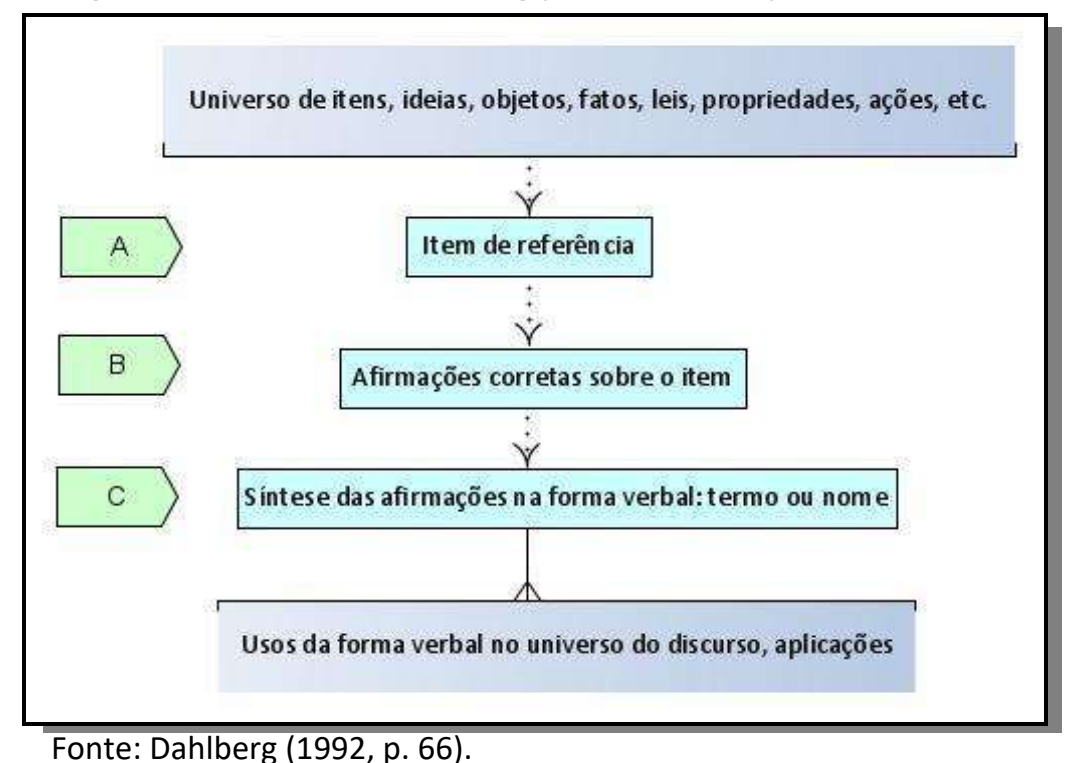

Conforme ressaltado, Dahlberg (1978a, b, c, d) indica uma fase analítica e uma fase sintética para se definir o conceito, motivo pelo qual a sua teoria também é denominada de Teoria Analítica do Conceito (GOMES; CAMPOS, 2019). Na fase analítica, "[...] cada enunciado verdadeiro representa um elemento do conceito." (DAHLBERG, 1992, p. 102). Nesse modelo teórico, o conceito representa uma unidade estruturada do conhecimento e cada enunciado que o compõe é concebido como um atributo ou característica. Um conjunto de características, por sua vez, determina um conceito. Na fase sintética, se "[...] o conceito ainda não tem um nome, é possível formulá-lo pela síntese das [suas] características [...]" (DAHLBERG, 1978d, p. 104). A síntese de todas as características, assim determinadas sob um nome ou um código, representa o conteúdo do referente, sendo a definição de um conceito o registro com o resumo das características determinantes do seu conteúdo (DAHLBERG, 1992, 2014).

Como observado, na Teoria do Conceito, três elementos, sintetizados no denominado triângulo conceitual, são fundamentais: a) o referente, b) as características e c) a forma verbal. Na Teoria do Conceito, subentende-se que todo conceito possui um referente - um objeto, um conjunto de objetos, uma atividade, um fato - sobre o qual podem ser feitas afirmações verificáveis ${ }^{4}$, determinando as propriedades e as relações do referente com outros

\footnotetext{
${ }^{4}$ Por "verificáveis", considera-se que Dahlberg se refere ao teor de verdade em algo, que tem relação ao sentido eidético das coisas (sua essência e não sua existência ou presença empírica). A autora menciona o "[...] conceito noemático do conhecimento [...] conhecido como resultado de um ato de cognição." (DAHLBERG, 2009, p. 170). Ela chama a atenção para a distinção que Karl Popper (1975) faz sobre o conhecimento objetivo, esclarecendo a intencionalidade (sentido imanente; referência intencional aos objetos) do mundo 3 (unidades de conhecimento) em relação ao mundo 2 (unidade de pensamento). Para Popper (1975), os três mundos são reais, independentes e ontologicamente distintos, sendo que o mundo 3
} 
referentes dentro do contexto analisado. Nessa perspectiva, a totalidade das afirmações verificáveis e verdadeiras de um referente pode ser sintetizada por um termo, que representa o conceito (DAHLBERG, 1978a). Dahlberg (1978a, b, c, d) parte, assim, do referente (item de referência) e propõe um modelo analítico para elucidar a natureza e a estrutura dos conceitos, conforme sintetiza a Figura 2.

Figura 2 - Modelo Analítico do Conceito

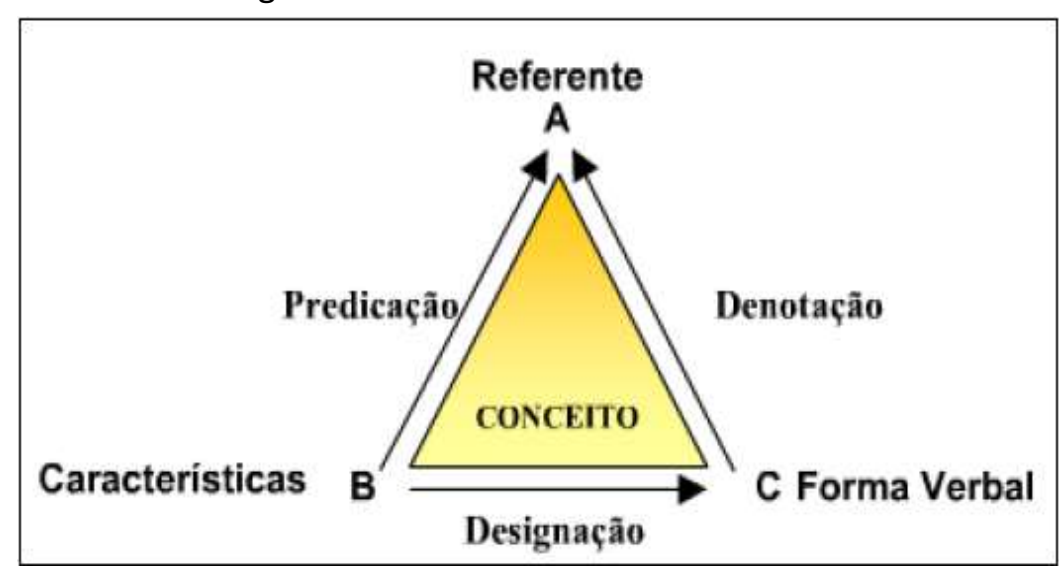

Fonte: Dahlberg (1978d, p. 149).

No Modelo Analítico do Conceito, apresentado na Figura 2, três elementos são importantes: a) o item de referência ou referente, que é o objeto a ser caracterizado; b) as afirmações verdadeiras, que expressam os atributos ou características do item de referência e c) a forma verbal, o termo, elemento comunicador que representa o conceito, devendo refletir a natureza do conceito, isto é, as características constitutivas do conceito (DAHLBERG, 1978d).

Então, resumidamente, para Dahlberg (1978a, b, c, 1992), o conceito é uma entidade abstrata (unidade do conhecimento), formada por um conjunto de características ou elementos de conhecimento, que tem o referente como elemento central. Em Dahlberg (1978a, b, c, d), o termo é a forma verbal que comunica o conceito e, junto com o objeto e as características, compõem o denominado triângulo conceitual. O conceito é, assim, a junção dos três elementos fundamentais, consequência de uma construção com base na análise e síntese dos seus elementos constitutivos, sendo o elemento nuclear para a organização do conhecimento.

É importante destacar, ainda, que, no momento da determinação das predicações e/ou características do conceito, podem ser identificadas categorias para a formação de estruturas conceituais de mesma natureza (CAMPOS, 2001), ou seja, com as mesmas características. Esse movimento é bastante útil na categorização de conceitos e formação de classes na estrutura de tesauros, como mostra a sistematização a seguir:

(mundo do conhecimento objetivo, objeto da epistemologia) é aquele composto pelos produtos da mente humana, sejam alusivas à produção de teorias, hipóteses ou argumentos, que se transformam e ampliam pela ação humana, agindo sobre o mundo 1 (material) por meio do mundo 2, dos eventos mentais. 0 autor justifica a concepção de que o mundo 3 pode ser considerado real com o fato de que as teorias científicas, por exemplo, têm efeito direto e indireto no mundo 1 (fornece o exemplo dos números primos e dos paradoxos da lógica), uma vez que a propriedade "real" pode ser atribuída a qualquer coisa que seja capaz de produzir um efeito, em qualquer nível, no mundo 1. 


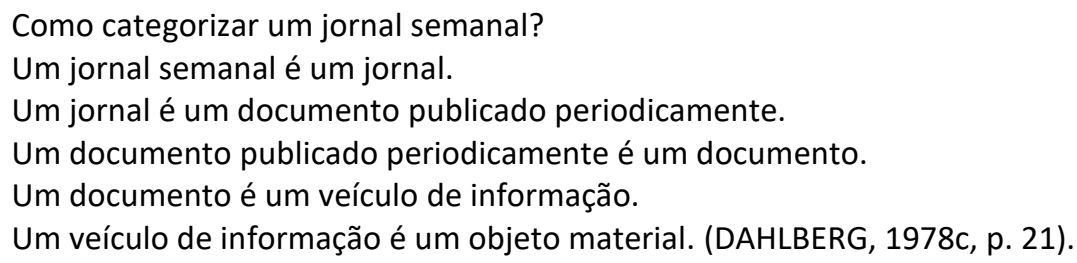

Por essa via de detalhamento das características do conceito, chega-se a um nível mais abstrato de representação, que corresponde à categoria e/ou nível mais abrangente de conhecimento. Para Dahlberg (2006), isso é possível porque a categoria aglutina "[...] unidades de conhecimento únicas [e] hierarquicamente superiores, [que] podem ser usadas como última declaração sobre um referente (por exemplo, é um objeto, um processo, uma propriedade, uma dimensão) [...]". A autora esclarece que as categorias possuem capacidade de estrutura para as unidades do conhecimento, fornecendo, "[...] simultaneamente, por este meio, o esqueleto, os ossos e tendões para estruturar todo o nosso conhecimento." (DAHLBERG, 1978c, p. 34). A concepção de categorias, em Dahlberg (2006), coaduna-se com os princípios aristotélicos de categorização do conhecimento. Aristóteles foi, sem dúvida, um grande inspirador para a elaboração da Teoria do Conceito e para grande parte das concepções teóricas sobre organização do conhecimento, no âmbito da Biblioteconomia e Ciência da Informação. Quadro 1.

Os principais elementos da Teoria do Conceito, de Dahlberg, são sintetizados no

Quadro 1 - Principais elementos da Teoria do Conceito de Dahlberg

\begin{tabular}{|c|c|c|c|}
\hline Conceito & Termo & Relações & Categoria \\
\hline $\begin{array}{l}\text { Unidade de conhecimen- } \\
\text { to formada pela síntese } \\
\text { de enunciados verdadei- } \\
\text { ros (características) sobre } \\
\text { um referente (objeto, } \\
\text { processo, dimensão, } \\
\text { propriedade) e fixada por } \\
\text { um símbolo linguístico } \\
\text { (DAHLBERG, 1978d). } \\
\text { As unidades do conheci- } \\
\text { mento são objetivas e, } \\
\text { portanto, verificáveis. São } \\
\text { resultado de um ato de } \\
\text { cognição (DAHLBERG, } \\
\text { 2009). }\end{array}$ & $\begin{array}{l}\text { Símbolo linguístico que } \\
\text { fixa e representa o con- } \\
\text { ceito com o propósito de } \\
\text { comunicá-lo (1978d). } \\
\text { “Qualquer modo de indi- } \\
\text { cação do conteúdo do } \\
\text { conceito” (DAHLBERG, } \\
2009, \text { p. 171). }\end{array}$ & $\begin{array}{c}\text { São definidas a partir das } \\
\text { características iguais, } \\
\text { semelhantes ou depen- } \\
\text { dentes funcionalmente } \\
\text { de um conceito em rela- } \\
\text { ção ao outro (DAHLBERG, } \\
\text { 2006). }\end{array}$ & $\begin{array}{l}\text { Possui função estrutural. } \\
\text { Aglutina as unidades de } \\
\text { conhecimento com as } \\
\text { mesmas características. }\end{array}$ \\
\hline
\end{tabular}

Fonte: elaborado pelas autoras (2020).

O estudo das características dos conceitos permite identificar elementos lógicos e comuns entre eles, que são a base para se construir relações conceituais e categorias nos tesauros. Esses processos são estreitamente relacionados com a elaboração de definições consistentes, conforme exposto na próxima seção.

\subsection{Definições em tesauros}

As definições permitem delinear a identidade do conceito e identificar suas principais características ou atributos. As definições nos tesauros podem ser construídas a partir dos 
princípios da Teoria do Conceito, cujos fundamentos são o estudo das características do referente, conforme abordado na seção anterior.

Destaca-se que, nas definições, o modelizador de tesauros obtém os elementos necessários à modelagem conceitual e construção das relações semânticas. Por meio de definições bem formuladas, é possível estabelecer relações entre conceitos com características semelhantes e fixar a posição de um conceito em determinado sistema nocional ${ }^{5}$, evidenciando as propriedades de um dado objeto (CAMPOS, 2001, 2016; GOMES; CAMPOS, 2019). Isso porque, quando há características semelhantes entre os conceitos, existe algum tipo de relação entre eles, estabelecida pelo compartilhamento de características comuns. Tal fenômeno indica que os conceitos se definem uns em relação aos outros (DAHLBERG, 1978d; GOMES; CAMPOS, 2019), formando, assim, um sistema conceitual ou nocional.

Dahlberg (1978a, b, c, 1981, 1983) propõe a elaboração de definições a partir dos aportes teóricos da Teoria do Conceito, cujas raízes são os fundamentos da filosofia aristotélica, conforme visto na seção anterior. Para Dahlberg (1983, p. 20), "Uma definição é a equivalência entre um definiendum (o que deve ser definido) e o definiens (como algo deve ser definido) para o propósito de delimitação da compreensão do definiendum em qualquer situação comunicativa." Desse modo, "O ato de definir é uma construção de aspectos selecionados do referente realizada pelo 'olhar' de um grupo que aquiesce sobre o seu entendimento em um dado espaço de conhecimento." (GOMES; CAMPOS, 2019, p. 40).

Na definição, é preciso explicitar as características dos conceitos, que são classificadas em essenciais e acidentais (DAHLBERG, 1981). Alinhada com o pensamento de Aristóteles, a autora afirma que as primeiras são fundamentais para se definir o conceito e existem em todos os referentes. Já as características acidentais são aquelas que podem ocorrer em alguns casos, em um dado referente, e são ilimitadas em número e tipo. Embora haja ressalvas que necessitam de análise específica, Dahlberg (1981) afirma que as características acidentes não devem ser mencionadas em uma definição. Segundo ela, em alguns casos, o gênero próximo e a diferença específica permitem construir a relação de um conceito com, pelo menos, dois outros conceitos.

$\mathrm{Na}$ definição também está presente a abordagem onomasiológica em Dahlberg (1981, 1983), que se refere à elaboração de predicações (asserções) sobre o referente. Esse tipo de abordagem - ao contrário da semasiológica - parte do conceito para o termo, que é a sua denominação e/ou forma externa. A abordagem onomasiológica "[...] é uma abordagem conceitual, que parte de uma perspectiva sistêmica na qual o conjunto dos termos [...] reflete a organização do conhecimento [no] domínio, ou seja, os termos denotam os conceitos." (GOMES; CAMPOS, 2019, p. 38).

Na concepção de Dahlberg (1983), parte-se do conceito para estabelecer-se as definições conceituais, que permitem a identificação das características do referente e a inserção do conceito em um sistema conceitual. As características são, assim, os elementos materiais e estruturais do conceito. Dahlberg $(1981,1983)$ defende, ainda, que as definições podem ser construídas tendo como subsídios as relações conceituais, por ela denominadas genéricas, partitivas e funcionais. A definição genérica adota, em sua estrutura, princípios da relação formal, referentes ao gênero próximo e à diferença específica, como mostrado no exemplo a seguir:

\footnotetext{
5 "O sistema de conceitos é fruto de uma visão do domínio estudado, podendo estruturar-se diferentemente, de acordo com os critérios empregados." (BARROS, 2004, p. 108).
} 


\section{- Exemplo $1^{6}$ :}

o drama = uma composição, em verso ou prosa, organizada para enaltecer, com intenção de retratar a vida...

O primeiro elemento dessa definição é o conceito superordenado (gênero próximo), em relação ao conceito que está sendo definido (composição) e, em sequência, apresentamse as características distintivas (diferenças específicas) que diferenciam os conceitos (em verso ou prosa, organizadas para enaltecer e com intenção de retratar a vida).

Já a definição partitiva identifica os componentes do conceito e parte do princípio de que o referente pode ser um todo cujas partes podem ser enumeradas como suas características. A relação partitiva pode ocorrer entre um todo e suas partes, como entre uma parte e o todo de um objeto. Outro exemplo de relação todo/parte encontra-se na descrição das etapas do desenvolvimento de um processo. A título exemplificativo, tem-se o processo de indexação na Biblioteconomia, que é composto pelas etapas: 1) análise de assunto e 2) tradução.

Por sua vez, a autora salienta que as relações funcionais são, frequentemente, usadas em definições conceituais e permitem identificar a função ou finalidade do referente, sendo também conhecidas como operacionais ou genéticas. Nesse tipo de relação, o referente é o resultado da ação ou da operação realizada sobre algo (referente), ou do processo sofrido pelo próprio referente, como:

\section{- Exemplo 2:}

o produto $=$ o número, na matemática, resultante da multiplicação de dois ou mais números.

Dahlberg (1983) destaca que a definição funcional pressupõe, ao menos, (a) um assunto lógico e (b) um predicado lógico, que também pode ser complementado por (c), conforme exemplo de análise do conceito produto, apresentado no Quadro 2:

Quadro 2 - Análise de definição funcional

\begin{tabular}{|l|l|}
\hline (a) dois ou mais números & objetos/assunto lógico \\
\hline (b) multiplicação & atividade: operação/predicado lógico \\
\hline (c) resultante de um número & objeto/complemento do predicado \\
\hline
\end{tabular}

Fonte: Dahlberg (1983, p. 24).

Dahlberg (1983) também defende que as definições genéricas, partitivas e funcionais podem ser formalmente subdivididas em diferentes tipos, a depender do contexto e dos tipos de diferenças específicas. Para a autora, há conceitos que, a depender do contexto e propósito, podem ser definidos por, pelo menos, dois ou mais tipos de definições, sendo que os mais recorrentes são os genéricos e os partitivos.

O padrão definitório proposto por Dahlberg $(1981,1983)$ classifica a definição conforme a categoria do conceito: genérica, partitiva ou funcional, mas a autora também destaca que a estrutura e o conteúdo de uma definição dependem, em grande parte, da intenção do autor em formulá-la (DAHLBERG, 1981). Corroborando essa concepção, Campos (2010) e Gomes e Campos (2019) destacam que o padrão definitório ideal é aquele que atende às especificidades da área, ao nível do conceito e à natureza categorial, explicitando as caracte-

\footnotetext{
${ }^{6}$ Os exemplos foram traduzidos de Dahlberg (1983).
} 
rísticas do conceito. Desse modo, pode-se considerar que as definições analíticas permitem situar o conceito em um sistema de conceitos, e as definições operativas coadunam-se com os propósitos práticos de uso dos conceitos em um dado contexto.

A partir dos pressupostos teóricos de Dahlberg $(1981,1983)$, Campos (2010) afirma que é necessário estabelecer um número mínimo de informações para caracterizar um referente, e, assim, construir um padrão definitório: 1) características que indiquem o gênero próximo e a diferença específica do conceito; 2) componentes do conceito ou suas etapas (se o conceito indicar um processo ou todo); e 3) a finalidade de aplicação no contexto do domínio. Tais informações correspondem ao tipo de definição que pode ser elaborada. De acordo com essa concepção, o gênero próximo, que inclui um grupo de conceitos com características comuns, indica o termo superordenado; que é distinguido, pela diferença específica, dos demais conceitos daquele mesmo gênero. A perspectiva da definição pelo elemento todo/parte indica os componentes de um objeto ou as etapas de desenvolvimento de um processo. E a definição funcional é construída a partir da indicação do que o conceito é (sua essência) pela função ou finalidade que ele exerce. Ressalta-se, no entanto, que essa função é distinta do traço semântico (diferença específica) da finalidade, enquanto elemento diferenciador do conceito.

Na concepção de Dahlberg $(1981,1983)$, o mais importante para se elaborar os sistemas definicionais é determinar o referente de um conceito, pois uma vez que o referente e suas características foram delimitados, o conceito é estabelecido. Há de se considerar, ainda, os traços semânticos constitutivos do conceito no domínio sob análise, o público-alvo e os propósitos para os quais as definições são elaboradas.

No âmbito da Terminologia, destaca-se a abordagem a partir da qual se elaboram definições com base na identificação de traços semânticos ou propriedades do objeto definido. Os traços semânticos variam de acordo com a natureza do conceito, com o contexto e o propósito para o qual as definições são elaboradas. A concepção de traço semântico equivale ao que Aristóteles e Dahlberg $(1981,1983)$ denominam de diferenças específicas, que, por sua vez, são compostas pelos traços semânticos. Nesse sentido, Balestero, Almeida e Pierozzi Júnior (2019) exemplificam, no Quadro 3, os tipos de traços semânticos e seus respectivos sentidos, aplicáveis ao campo de estudos da intensificação agropecuária.

Quadro 3 - Exemplos de traços semânticos no campo da intensificação agropecuária

\begin{tabular}{|l|l|}
\hline Aspecto = aparência exterior & Finalidade = objetivo, propósito, fim \\
\hline Característica = particularidade do conceito & $\begin{array}{l}\text { Instrumento = objeto, meio ou recurso empregado } \\
\text { para se atingir um fim }\end{array}$ \\
\hline Causa = motivo gerador de algo & Local = localização espacial \\
\hline $\begin{array}{l}\text { Composição = constituição de ou maneira como algo } \\
\text { se constitui }\end{array}$ & $\begin{array}{l}\text { Origem = ponto de partida, ponto inicial de algo, } \\
\text { procedência }\end{array}$ \\
\hline Consequência = resultado ou efeito de algo & Período = tempo \\
\hline \multicolumn{2}{|c|}{ Função = utilidade de algo, emprego, serventia } \\
\hline
\end{tabular}

Fonte: Balestero, Almeida e Pierozzi Júnior (2019, p. 14).

Os traços semânticos apresentados no Quadro 3 foram identificados pelos autores a partir de excertos definitórios provenientes de várias fontes. Assim, “[...] quanto maior o número de excertos para cada termo, melhor, porque mais informações teremos sobre o 
termo a ser definido, o que ajuda a assegurar uma DT [definição terminológica] mais completa." (BALESTERO; ALMEIDA; PIEROZZI JÚNIOR, 2019, p. 13). A metodologia para se identificar os traços semânticos é descrita por Kamikawachi (2009):

1) seleção do campo semântico e dos seus respectivos termos;

2) elaboração de uma base definicional contendo definições de fontes diversas e contextos explicativos para um mesmo termo;

3) observação, seleção e sistematização dos traços semânticos: primeiro, observamse os traços semânticos recorrentes na explicação dos termos; depois, realizamse a seleção e sistematização desses traços com o objetivo de verificar quais são importantes para compor a definição terminológica e qual a melhor ordem; por fim, realiza-se a sistematização desses traços;

4) elaboração de um modelo que orientará a redação das definições terminológicas de todos os termos do campo semântico escolhido;

5) redação da definição terminológica;

6) validação da definição terminológica pelo especialista no domínio;

7) inserção da definição na ficha terminológica.

Os traços semânticos são empregados na segunda parte da definição, seguindo-se ao termo superordenado em uma definição do tipo gênero próximo e diferença específica. Nesse tipo de definição, empregam-se regras que apresentam o termo superordenado, seguido dos traços semânticos que o distingue de outros termos. Deve-se considerar que o padrão definitório a ser utilizado em um campo de assunto depende, primeiro, da análise da estrutura da definição em várias fontes de informação, e, depois, da elaboração de uma espécie de modelo com os principais traços semânticos adotados naquela definição (BALESTERO; ALMEIDA; PIEROZZI JÚNIOR, 2019). Ademais, para um conjunto de termos de uma mesma área temática, podem ser elaboradas definições com o emprego de traços semânticos distintos.

Para a compreensão da aplicação de traços semânticos na definição terminológica, Kamikawachi (2009) apresenta, no Quadro 4, o exemplo referente ao termo carbonato de cálcio. A análise, pela autora, dos excertos definitórios em diversas fontes de informação possibilitou a identificação dos seguintes traços semânticos para esse termo: 1) o que é (ou termo superordenado/hiperônimo); 2) constituição; 3) propriedades; 4) origem; 5) emprego. Após a identificação e sistematização desses traços semânticos, a definição terminológica foi elaborada pela autora.

Quadro 4 - Exemplos de traços semânticos referentes ao termo carbonato de cálcio

Carbonato de cálcio: [carbonato]1 [sólido branco, insolúvel em água, decompõe-se por aquecimento, formando-se óxido de cálcio (cal viva) e dióxido de carbano]2. [Branqueador, torna o esmalte mais duro e resistente, além de propiciar baixo coeficiente de expansão térmica]3. [Ocorre na natureza como os minerais calcita e aragonita.]4 [É a matéria-prima mais utilizada para introduzir cálcio em massas e esmaltes. Empregado na composição da maioria dos esmaltes.] 5.

Fonte: Kamikawachi (2009, p. 48).

É importante destacar que o modelizador deve analisar, refletir e definir os traços semânticos, a partir da natureza do conceito e das características do domínio ${ }^{7}$ e do contexto

\footnotetext{
${ }^{7}$ Aqui se considera domínio conforme concepção de Hjørland e Albrechtsen (1995), podendo ser: área de conhecimento (especialidade científica ou não), conjunto literário, atividades e tarefas, ou missões.
} 
no qual ele se insere. Isso pode ser evidenciado em uma breve comparação de conceitos em áreas diferentes do conhecimento. Na Química, por exemplo, tomando os conceitos de sais e hidrocarbonetos, logo se pensa nas características, propriedades, origem, composição e função desses elementos. Por sua vez, quando se analisa um movimento teórico da Literatura, como o Realismo, os elementos caracterizadores desse conceito reportam à sua origem, características que o contrapõem a um outro movimento, seus principais expoentes ou os motivos/causas do seu surgimento. Na Medicina, por outro lado, uma determinada doença possui causa, sintomas, características específicas e provoca consequências na saúde do indivíduo. Já na Mecânica, os equipamentos possuem uma função, uma determinada finalidade e estrutura.

Uma vez que os elementos semânticos também subsidiam o estabelecimento de relações na estrutura dos tesauros, a próxima seção trata sobre eles.

\subsection{Semântica nos tesauros}

O entendimento da semântica e/ou significado do conceito nos tesauros é uma construção possibilitada por aportes teóricos de diversos domínios do conhecimento. A palavra semântica reporta-se ao verbo grego semaíno, cujo valor é significar, sendo, pois, a ciência das significações (LYONS, 1977; BARROS, 2003; LOPES, 2008). A semântica é, desse modo, um campo teórico amplo e heterogêneo, que tem por objeto a descrição das significações próprias às línguas (TAMBA-MECZ, 2006). Os primeiros estudos sobre o significado remontam aos gregos, que, mesmo antes de Platão, discutiam os problemas da relação entre a palavra e o ser, entre os signos e o universo (BARROS, 2003).

Nessa perspectiva, Pottier (1977) analisa o conteúdo semântico de uma palavra por meio de traços semânticos mínimos e/ou semas, pois é a partir da identificação das características ou semas dos objetos, e a comparação entre eles, que são constituídos os campos semânticos de um mesmo assunto. Lopes (2008) apresenta um exemplo para os termos cadeira e poltrona, conforme síntese apresentada no Quadro 5:

a) apresentam os semas comuns $[s 1+s 2+s 3+s 4]^{8}$;

b) 'poltrona' possui, além dos semas presentes em (a) acima, mais [s5] (o sema 'com braços');

c) 'cadeira' possui, além dos semas presentes em (a) acima, mais um sema relativo [s5], marcado negativamente, e que define 'cadeira' relativamente àquilo que nela falta quando a comparamos com 'poltrona'. (LOPES, 2008, p. 267).

Segundo o autor, percebe-se que, por estarem em um mesmo campo semântico, implica dizer que os termos cadeira e poltrona se definem um em relação ao outro. No Quadro 5 , apresentam-se os semas dos objetos do campo semântico das mobílias.

Quadro 5 - Levantamento de semas de objetos do mesmo campo semântico

\begin{tabular}{|l|c|c|c|c|c|c|c|}
\hline & $\mathrm{s} 1$ & $\mathrm{~s} 2$ & $\mathrm{~s} 3$ & $\mathrm{~s} 4$ & $\mathrm{~s} 5$ & $\mathrm{~s} 6$ & \\
\hline cadeira & + & + & + & + & - & + & $=\mathrm{S} 1$ \\
\hline poltrona & + & + & + & + & + & + & $=\mathrm{S} 2$ \\
\hline tamborete & - & + & + & + & - & + & $=\mathrm{S} 3$ \\
\hline canapé & + & + & - & + & + & + & $=\mathrm{S} 4$ \\
\hline pouf & - & + & + & + & - & - & $=\mathrm{S} 5$ \\
\hline
\end{tabular}

Fonte: Lopes (2008, p. 268).

\footnotetext{
${ }^{8}$ Ver Quadro 5.
} 
Nos Quadros 5 e 6, apresenta-se o levantamento de semas dos objetos do campo semântico das mobílias.

Quadro 6-Significado dos semas do campo semântico das mobílias

\begin{tabular}{|ll|}
\hline s1 $=$ com encosto & s4 = para sentar-se \\
s2 $=$ com pé(s) & $s 5=$ com braços \\
s3 $=$ para uma pessoa & $s 6=$ com material rígido \\
\hline
\end{tabular}

Fonte: Lopes (2008, p. 268).

Observa-se, pela análise dos Quadros 5 e 6, que cada semema (conjunto de semas) apresenta, ao mesmo tempo, um aspecto conjuntivo que o integra ao campo semântico, e um aspecto disjuntivo refletidor de sua diferença específica e responsável por individualizálo em relação aos demais sememas desse campo. Assim, apenas dois semas (s2 e s4) estão presentes em todos os sememas, o que permite que eles definam o semema de assento, o qual, por sua vez, é a base comum do campo semântico, isto é, um arquilexema (LOPES, 2008).

Ainda no contexto da semântica, Pottier (1977) sugere a elaboração de definições para os conceitos e a constituição de campos semânticos associativos, a partir de níveis de informações, como nos exemplos:

$$
\begin{aligned}
& \text { Cadeira = tamborete com encosto } \\
& \text { Poltrona = cadeira com braços } \\
& \text { Sofá = poltrona para mais de uma pessoa }
\end{aligned}
$$

Segundo Pottier (1977, p. 26), ocorrem, também, as formulações por inclusões sucessivas:

Banco: assento estreito e comprido, guarnecido ou não de encosto.

Assento: móvel ou qualquer outro objeto colocado de modo que alguém possa nele sentar-se.

Móvel: qualquer objeto móvel que sirva para uso e decoração das habitações.

Objeto: tudo aquilo que se oferece à vista.

O exemplo acima demonstra a perda de um número de semas distintivos à medida que são apresentadas as definições de banco a objeto. Ao final, permanece apenas o suporte desses semas, ou seja, o classema, que se assemelha ao conceito de classe por reunir elementos com características comuns.

No contexto da representação da informação, Kobashi (2007, on-line) destaca a importância da teoria dos campos semânticos, desenvolvida durante as décadas de 1920 e 1930 pelos linguistas alemães Jost Trier (1894-1970) e Johann Leo Weisgerber (1899-1985), segundo a qual o vocabulário de uma língua se compõe de subconjuntos de campos semânticos. O campo semântico é toda área de significação de uma palavra ou de um grupo de palavras, que tem por fundamento o princípio da associação e da interdependência entre elas, tal como aponta Lopes (1976, p. 242):

conjunto de classificações correlatas que associam um grupo de palavras ou ainda a possibilidade que as unidades lexicais de uma língua têm de se reunir em grupos estruturados, de tal modo que cada unidade fica definida pelo lugar que ocupa respectivamente à posição das demais. 
"Nessa teoria, a noção de léxico, como conjunto estruturado de unidades lexicais reunidas em grupos estruturados, suplanta a ideia de que a língua é uma simples soma de vocábulos." (KOBASHI, 2007, on-line). Reconhece-se, ainda, que os domínios de conhecimento se expressam por termos, unidades com significados especializados, por isso a teoria dos campos semânticos trata da análise do sentido. Essas unidades e suas relações semânticas, integradas do ponto de vista do sentido, encontram-se num fluxo constante e mudam constantemente com o tempo, tal como a dinâmica da língua (LYONS, 1977).

Os elementos que compõem o campo léxico-semântico estão reunidos em uma intrincada rede de associações, que, por vez, podem originar novos campos semânticos. Nesses campos, há um conjunto de relações de sentido entre os vocábulos, formado a partir do processo cognitivo das associações semânticas, que permite articular um campo conceitual a um campo lexical (TAMBA-MECZ, 2006). A estruturação desses campos ocorre a partir de associações mnemônicas, cujo ponto de partida é aleatório, e que possibilitam estruturar categorias, agrupar conceitos e estabelecer relações lógico-linguísticas entre elas (CUNHA, 1990). Como exemplo, apresenta-se, nos Quadros 7 e 8, a formação de um campo semântico.

Quadro 7 - Campo semântico I do termo embarcação

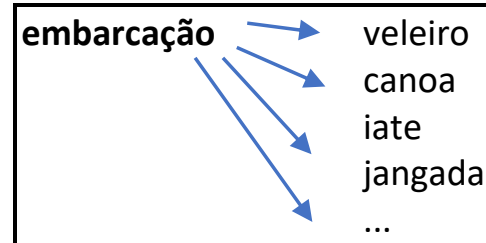

Fonte: Lopes, (2008, p. 259), adaptado de Dubois et al. (1974).

O exemplo apresenta a formação de um campo semântico estabelecido a partir das palavras ligadas ao termo embarcação. A aplicação continuada da associação pode originar outros campos semânticos, como demonstrado no Quadro 8.

Quadro 8 - Campo semântico II do termo embarcação

embarcação $\longrightarrow \begin{aligned} & \text { veleiro } \\ & \text { canoa } \\ & \text { iate } \\ & \text { jangada }\end{aligned} \longrightarrow \begin{aligned} & \text { proa } \\ & \text { casco } \\ & \text { vela } \\ & \ldots\end{aligned}$
$\ldots$

Fonte: Lopes (2008, p. 260).

Nesse exemplo, numa leitura vertical, a primeira coluna relaciona-se ao campo semântico das embarcações, compondo uma mesma classe paradigmática, que indica os tipos de embarcação; e a terceira coluna resume o campo semântico das partes constituintes dos veleiros. Uma leitura horizontal evidencia as relações sintagmáticas de inclusão, do termo mais genérico para o mais específico (da esquerda para a direita), sendo que da direita para a esquerda ocorre o inverso (LOPES, 2008).

Sobre os campos semânticos, pode-se aplicar a proposta de segmentação dos textos com a técnica da gramática baseada em noções lógicas de casos de Fillmore (1977), e os casos conceituais de Pottier $(1974,1977)$, os quais se aproximam da concepção de indicadores de função de Gardin (1970, 1973a, b). Para esses estudiosos, as redes lógico-semânticas são derivadas do campo semântico e dos casos conceituais - "[...] conceitos que permitem isolar 
universais linguísticos e categorizá-los operacionalmente no processo de construção de linguagens documentárias." (KOBASHI, 1989, p. 50). As noções de caso para Fillmore (1977, p. 299):

[...] incluem um conjunto de conceitos universais, presumivelmente inatos, que identificam certos tipos de julgamentos que os seres humanos são capazes de fazer acerca dos acontecimentos que ocorrem a seu redor, julgamentos acerca de assuntos tais como quem fez, com quem aconteceu, e o que foi mudado.

Assim, para Fillmore (1977), o conceito de 'caso' determina fenômenos sintáticosemânticos em que as relações casuais, ou casos, formam um conjunto de conceitos universais ou julgamentos sobre os acontecimentos, como Quem fez isso? Com o quê? A quem isso aconteceu? Em que lugar?, com o propósito de identificar conceitos significativos. Cunha (1990) defende que essas perguntas representam casos universais por meio dos quais é possível encontrar as categorias necessárias para a ordenação dos campos semânticos, possibilitando a estruturação de uma linguagem documentária. Fillmore (1977) apresenta os seguintes casos:

- $\quad$ agentivo (A): refere-se ao caso do agente animado da ação identificada pelo verbo:

- Exemplos: José abriu a porta; a porta foi aberta por José.

- $\quad$ instrumental (I): relaciona-se ao "caso da força ou objeto inanimado, causalmente implicado na ação ou estado identificados pelo verbo" (FILLMORE, 1977, p. 300):

- Exemplo: José abriu a porta com a chave.

- $\quad$ dativo (D): o caso do ser animado que é afetado pelo estado ou ação do verbo.

- Exemplo: Nós persuadimos José de que ele venceria.

- $\quad$ factivo (F): ocorre quando "o caso do objeto ou ser resultante da ação ou estado identificados pelo verbo, ou compreendido como parte do significado do verbo" (FILLMORE, 1977, p. 300); o caso factivo é construído com verbos factivos, cuja função é indicar que o locutor se compromete com a verdade da proposição expressa na oração complemento, tal como ocorre com os verbos, compreender, saber e perceber (INSTITUTO DE LINGUÍSTICA TEÓRICA E COMPUTACIONAL, [200-]).

- Exemplo: José sabe que Maria é uma boa escritora de poemas.

- locativo (L): é o "caso que identifica a localização ou orientação espacial do estado ou ação identificados pelo verbo" (FILLMORE, 1977, p. 300).

○ Exemplo: José mora em Chicago.

- $\quad$ objetivo (0): caso semanticamente mais neutro, conforme Fillmore (1977), também denominado ergativo, relaciona-se ao conceito (substantivo) afetado pela ação ou estado identificados pelo verbo.

- Exemplo: Chicago está chuvosa.

Os casos acima citados podem ser combinados uns com os outros e distinguidos pelos tipos de verbos, como, por exemplo, o verbo morder, que exige um agente. Em Fillmore (1977), são apresentadas complexas combinações entre esses casos, que se refletem na estrutura das sentenças e na posição dos seus elementos, como sujeito, verbos e objeto. Ade- 
mais, a inclusão ou exclusão dessas categorias ou casos dependerá das relações paradigmáticas na formação do campo semântico (CUNHA, 1990).

Por sua vez, Pottier $(1974,1977)$ propõe 11 casos conceituais para determinar o encadeamento lógico do enunciado, a saber: 1) agentivo; 2) locativo; 3) causativo; 4) instrumental; 5) beneficiativo; 6) dativo; 7) nominativo; 8) ergativo; 9) acusativo; 10) associativo e 11) finalidade, os quais permitem a formação de categorias gerais nos tesauros. Desse modo, a organização dos termos em categorias ocorre em função das perguntas sugeridas e nas quais esses casos conceituais estejam presentes.

Pelo exposto, observa-se que a palavra é portadora de uma gama de significações e sentidos, que variam de acordo com o contexto. Essa é uma característica da linguagem natural, para a qual as relações entre forma significante e significado são diversas, ao contrário das linguagens construídas, tal como o tesauro, que objetiva estabelecer uma correspondência uniforme entre a forma significante e o significado (CINTRA et al., 2002).

Depreende-se, assim, a função informativa e comunicativa dos tesauros, cujo objetivo primordial é a normalização conceitual e a fixação de significados num campo de especialidade para a representação e posterior recuperação da informação.

O estudo da semântica nos tesauros, segundo os aportes teóricos da Linguística, complementa-se com as recomendações normativas aplicáveis à criação de relações semânticas nos instrumentos terminológicos, conforme abordado na próxima seção.

\subsection{Relações semânticas na estrutura conceitual de tesauros}

Conforme abordado na seção anterior, os conceitos nos tesauros estão intimamente relacionados ao estudo da semântica (significado), haja vista que o conjunto das relações semânticas proporciona, aos tesauros, a característica de estrutura relacional. Segundo Hjørland (2007, p. 390), "As relações semânticas são as relações entre conceitos, significados ou sentidos [...]", cuja função é "[...] contribuir para o aumento da revocação e da precisão na recuperação da informação." (HJØRLAND, 2007, p. 392). Nos tesauros, os termos relacionam-se uns com os outros conforme indicações estabelecidas pelo seu próprio significado.

A ISO 25.964-1 (2011), que substitui a ISO 2788 (1986), destaca nos tesauros as relações hierárquicas, as associativas e as de equivalência. Além de abordar relações conceituais, estudo sobre termos, definições e aspectos da gestão de tesauros, a ISO 25.964-1 (2011) também retrata os aspectos da interoperabilidade dos tesauros com outros SOCs, incluindo o estudo sobre modelos de dados, esquemas, protocolos e formatos para intercâmbio de dados entre distintos sistemas. Esses aspectos técnicos também devem ser considerados na revisão e atualização de tesauros, especialmente no que diz respeito à consulta e ao reúso de terminologia e de estrutura conceitual advinda de outros vocabulários.

Segundo recomenda a norma, as relações hierárquicas devem ser estabelecidas quando o escopo de um conceito é complementado com o escopo do outro, baseando-se em níveis ou graus de superordenação e subordinação, no qual o conceito superordenado representa uma classe ou o todo, e os conceitos subordinados se referem aos seus membros ou partes. Assim, as classes de mesmo nível de divisão são coordenadas, pois compartilham um conjunto de propriedades, e os vários níveis de classes podem ser organizados de acordo com a sua endentação. Conforme a ISO 25.964-1 (2011) destaca, cada conceito subordinado deve pertencer à mesma categoria do seu conceito superordenado, como coisa, ação ou propriedade, dentre outras possibilidades. 
Na ISO 25.964-1 (2011), as relações hierárquicas podem ser de três tipos: I) genérica, II) todo-parte e III) de instância, representadas pelas siglas em inglês, respectivamente: BT (Broader term) e NT (Narrower term), ou BTG (Broader term generic) e NTG (Narrower term generic); BTP (Broader term partitive) e NTP (Narrower term partitive); e BTI (Broader term instance) e NTI (Narrower term instance), que correspondem às seguintes situações lógicas:

- Relação genérica: ligação entre uma classe ou categoria e seus membros ou espécies, identificada por meio do teste lógico: "todo/alguns". Assim, todos os papagaios são pássaros e alguns pássaros são papagaios, conforme exemplo da seção 10.2 da ISO 25.964-1 (2011).

- Relação todo-parte (partitiva): essa relação cobre um conjunto limitado de situações em que a parte de uma entidade ou sistema pertence unicamente a um todo. Conforme a norma internacional, neste caso também há uma posição de subordinação e superordenação, que se aplica, principalmente, a quatro principais classes de termos:
- Sistemas e órgãos do corpo.
- Localizações geográficas.
- Disciplinas ou campos do conhecimento.
- Estruturas hierárquicas sociais.

Outros exemplos aplicáveis às relações partitivas encontram-se entre os termos sistema nervoso central e sistema nervoso, que, segundo a norma internacional, também são identificados por BT/NT (TG/TE, em português).

- Relação de instância: ocorre entre um conceito geral, que pode ser uma classe de coisas ou eventos, e uma instância individual dessa classe, que é frequentemente representada por um nome próprio.

As relações associativas ocorrem na associação entre pares de conceitos que não são relacionados hierarquicamente, mas que estão semântica ou conceitualmente associados. 0 relacionamento associativo possui a representação internacional indicada pela sigla $\mathrm{RT}$ ( $R e$ lated Term), em inglês, e deve ser aplicado reciprocamente. Na relação associativa, um termo é componente necessário na definição do outro termo; assim, o termo pássaro, por exemplo, compõe uma parte necessária da explanação de ornitologia, e vice-versa (ISO, 2011).

Ainda segundo diretrizes da ISO 25.964-1 (2011), as relações de equivalência são aquelas existentes entre um termo preferido e seu correspondente termo não preferido, em linguagem natural. Esse tipo de relacionamento é representado, conforme convenção internacional, pelas siglas USE/UP (Use for ou Used for). A importância das relações de equivalência encontra-se na possibilidade de conferir mais pontos de acesso para facilitar a pesquisa do usuário, pois é nessas relações que se encontra o controle terminológico.

Outra situação para a ocorrência das relações de equivalência, segundo a ISO 25.9641 (2011), diz respeito à possibilidade de tratar-se o nome da classe e o nome dos seus membros como equivalentes, de forma que o termo geral funcione como termo preferido. Essa é uma técnica para reduzir o número de termos preferidos em um tesauro. Por sua vez, há a ocorrência de relações de equivalência que se refere à representação de conceitos complexos a partir de uma combinação de termos, como, por exemplo:

Mineração de carvão

USE Carvão + mineração 
A norma recomenda que todas as decisões quanto à priorização de uma forma ou de outra sejam registradas na apresentação do instrumento terminológico, e levem em consideração a amplitude da sua cobertura temática.

Outra recomendação da norma se refere à possibilidade de as relações semânticas serem customizadas para atender aos propósitos da modelização conceitual. Assim, pode ser criada uma simbologia própria, diversa da forma convencional estabelecida na norma, tendo em vista especificar um tipo de relação semântica. Nesse contexto, há os exemplos de CAUSA/EFEITO para definir um tipo de relação associativa ou TC/AB para indicar uma relação de equivalência referente a um termo completo e a uma abreviatura.

Observa-se, assim, a necessidade da observância dos critérios normativos para se construir as relações semânticas nos tesauros. É preciso que tais relações, para serem consistentes, superem os aspectos puramente cognitivos, muitas vezes empregados na associação dos conceitos, e sejam construídas com base em aspectos teórico-normativos.

\section{CONTRIBUIÇÕES DO REFERENCIAL TEÓRICO PARA A PESQUISA EMPÍRICA}

Durante a pesquisa empírica, que se referiu ao desenvolvimento da modelagem conceitual em um protótipo de tesauro no recorte temático da Contabilidade Patrimonial, foi possível aplicar o referencial teórico, apresentado na seção 2, na estruturação conceitual do instrumento terminológico. O esquema de categorias PMEST, de Ranganathan (1967), foi utilizado na definição das classes básicas do tesauro, indicando os objetos (materiais/imateriais), atributos, processos, e o aspecto temporal que essas classes refletiam. Os princípios analítico-sintéticos foram observados na organização e entendimento dos assuntos e dos sistemas conceituais. Os fundamentos teóricos da TCF sobre os planos das ideias, plano verbal e plano notacional permitiram pensar a concepção e a estrutura conceitual do protótipo de tesauro. A concepção de faceta foi observada na organização dos conceitos nas classes e subclasses do tesauro, aplicando-se um único princípio de divisão a cada vez. Os princípios para a formação de assuntos, por sua vez, subsidiaram os processos de formação e agrupamento de conceitos.

Os aportes da Teoria do Conceito, desenvolvida por Dahlberg (1978a, b, c, d) foram fundamentais para se entender as características dos conceitos e a distinção entre conceito (unidade de conhecimento) e sua representação (o termo), elemento comunicativo, tendo como pressuposto norteador a concepção de referente.

A elaboração de definições, a partir do padrão definitório pautado nos insumos teóricos apresentados na seção 2.3, foi um grande diferencial para subsidiar a modelagem conceitual. Com as definições, foi possível construir a identidade dos conceitos e analisar suas principais características, similaridades e diferenças com outros conceitos. As definições foram especialmente importantes na construção das relações associativas, que se revelaram as mais complexas, por suscitarem a subjetividade do modelizador. Assim, por meio das definições, foram obtidos os insumos para construir-se relações semânticas hierárquicas, associativas e de equivalência, e, assim, estruturar todo o sistema conceitual. Evidenciou-se que o padrão definitório construído para apoiar a modelagem conceitual deve basear-se nos traços semânticos característicos dos conceitos do domínio com o qual se trabalha. Observouse, assim, que a compreensão da semântica dos conceitos nos tesauros envolve uma dimensão mais ampla, que deve considerar as definições - elaboradas segundo as diretrizes de um padrão definitório próprio para o domínio - os aportes teóricos da linguística sobre campos semânticos e as recomendações das normas internacionais aplicáveis aos tesauros. 


\section{CONSIDERAÇÕES FINAIS}

Os tesauros são instrumentos de representação da informação que refletem a complexidade e a dinamicidade da linguagem. Devido a essas características, há a necessidade de que eles sejam revisados e atualizados segundo critérios científicos e normativos, para que reflitam a consistência semântica necessária à representação do domínio modelizado, assim como sejam eficientes mecanismos de recuperação da informação.

A partir da revisão narrativa, sem a intenção de esgotar o assunto, foi possível mapear e analisar uma vasta literatura acerca da construção, revisão e atualização de tesauros, busca que evidenciou os principais aportes teórico-conceituais considerados aplicáveis ao tema.

Sendo assim, foram apresentados, neste trabalho, os fundamentos teóricos que perpassaram pela TCF e Teoria do Conceito (Biblioteconomia e Ciência da Informação), pelos aportes teóricos da Terminologia e da Linguística, incluindo insumos para a elaboração de definições e para a compreensão da semântica e dos campos semânticos. Também se evidenciou a importância de considerar-se as recomendações normativas na construção, revisão e atualização de tesauros, sendo apresentada a ISO 25.964-1 (2011), que é a norma mais atual.

Na pesquisa empírica, que se relacionou ao desenvolvimento de um protótipo de tesauro, foram fundamentais todos os fundamentos descritos na seção 2 . Durante a modelagem conceitual, revelaram-se imprescindíveis os aportes teóricos sobre construção de definições, condizentes com os objetivos da pesquisa e as características do domínio modelado.

\section{REFERÊNCIAS}

BALESTERO, M. S.; ALMEIDA, G. M. B.; PIEROZZI JÚNIOR, I. Quando o especialista de domínio e as novas tecnologias entram em cena: impactos na definição terminológica. Revista Linguagem, São Carlos, v. 30, n. 1, p. 1-27, jan./jun. 2019.

BARITÉ, M. Diccionario de organización del conocimiento: clasificación, indización, terminologia. Montevideo: Universidad de la República Uruguay, 2015.

BARROS, C. M. P. A semântica e o discurso. In: CONGRESSO NACIONAL DE LINGUÍSTICA E FILOLOGIA, 7., 25 a 29 de agosto de 2003, Rio de Janeiro. Anais [...]. Rio de Janeiro: UERJ, Cadernos do CNLF, v. 7, n. 7, 2003. Disponível em:

http://www.filologia.org.br/viicnlf/anais/caderno07-02.html. Acesso em: 5 maio 2019.

BARROS, L. A. Curso básico de terminologia. São Paulo: EDUSP, 2004. (Acadêmica; 54)

CAFÉ, L. M. A.; BRATFISCH, A. Classificação analítico-sintética: reflexões teóricas e aplicações. TransInformação, Campinas, v. 19, n. 3, p. 237-250, set./dez. 2007. Disponível em: https://www.scielo.br/pdf/tinf/v19n3/04.pdf. Acesso em: 22 set. 2019.

CAMPOS, M. L. A. Emprego da abordagem onomasiológica na elaboração de definições em ontologias de domínio: estudo preliminar. In: SEMINÁRIO DO GRUPO DE PESQUISA MHTX, 2., 2016, Belo Horizonte. Anais [...]. Belo Horizonte: ECI/UFMG, 2016. p. 78-82. Disponível em: https://www.embrapa.br/busca-de-publicacoes/-/publicacao/1046505/pesquisa- 
integrada-em-organizacao-do-conhecimento-e-recuperacao-da-informacao-anais. Acesso em: 13 jan. 2019.

CAMPOS, M. L. A.; GOMES, H. E. Tesauro e normalização terminológica: o termo como base para intercâmbio de informações. Datagramazero - Revista de Ciência da Informação, Rio de Janeiro, v. 5, n. 6, 2004. Disponível em:

https://www.brapci.inf.br/index.php/res/download/44864. Acesso em: 22 set. 2019.

CAMPOS, M. L. A. Linguagem documentária: teorias que fundamentam sua elaboração. Niterói, RJ: Editora da Universidade Federal Fluminense, 2001.

CAMPOS, M. L. A. O papel das definições na pesquisa em ontologia. Perspectivas em Ciência da Informação, Belo Horizonte, v. 15, n. 1, p. 220-238, jan./abr. 2010. Disponível em: http://portaldeperiodicos.eci.ufmg.br/index.php/pci/article/view/945/683. Acesso em: 4 jan. 2019.

CINTRA, A. M. M. et al. Para entender as linguagens documentárias. 2. ed. rev. ampl. São Paulo: Polis, 2002.

CORDEIRO, A. M. et al. Revisão sistemática: uma revisão narrativa. Rev. Col. Bras. Cir., Rio de Janeiro, v. 34, n. 6, p. 428-431, 2007.

CUNHA, I. M. R. F. Do mito à análise documentária. São Paulo: Editora da Universidade de São Paulo, 1990.

DAHLBERG, I. A referent-oriented analytical concept theory of interconcept. International Classification, Frankfurt, v. 5, n. 3, p. 142-150, 1978a. Traduzido do inglês por Vânia Teixeira Gonçalves. Manuscrito.

DAHLBERG, I. Brief communication: concepts and terms: ISKO's major challenge. Knowl. Org., v. 36, n. 2/3, p. 169-177, 2009.

DAHLBERG, I. Brief communication: what is Knowledge Organization? Knowl. Org. v. 41, n. 1, p. 85-91, 2014a.

DAHLBERG, I. Conceptual definitions for Interconcept. Intern. Classificat, Frankfurt, v. 8, n. 1, p. 16-22, 1981.

DAHLBERG, I. Current trends in knowledge organization. 2014b. Disponível em: http://www.iskoiberico.org/wp-content/uploads/2014/07/007-026_Dahlberg.pdf. Acesso em: 16 abr. 2019.

DAHLBERG, I. Definitionen aus dem Begriffsfeld “Wissensorganisation". 2006. Disponível em: https://isko-de.org/beitraege/dahlberg-definition/?fbclid=IwAR1 spFatgTeAfgUX6pPIpW xlh20 UI7MetoE7SG 28EVaabc3CnbCn4A. Acesso em: 14 abr. 2019. 
DAHLBERG, I. Fundamentos teórico-conceituais da classificação. Revista de Biblioteconomia de Brasília, v. 6, n.1, p. 9-21, 1978b. Disponível em:

https://periodicos.unb.br/index.php/rbbsb/article/view/29057/24860. Acesso em: 16 abr. 2019.

DAHLBERG, I. Knowledge organization and terminology: philosophical and linguistic bases.

Int. Classif., v. 19, n. 2, p. 65-71, 1992.

DAHLBERG, I. Ontical structures and universal classification. Bangalore: Sarada Ranganathan Endowment, 1978c. 64 p.

DAHLBERG, I. Teoria do conceito. Ciência da Informação, Rio de Janeiro, v. 7, n. 2, p. 101107, 1978d. Disponível em: http://revista.ibict.br/ciinf/article/view/115/115. Acesso em: 25 fev. 2019.

DAHLBERG, I. Terminological definitions: characteristcs and demands. In: COLLOQUE INTERNATIONAL DE TERMINOLOGIE, 1982, Quebec. Actes [...]. Problèmes de la définition et de la synonymie en terminologie. [Quebec]: ASSOCIATION INTERNATIONALE DE TERMINOLOGIE, Université Laval, [1983]. p. 15-34.

FILLMORE, C. J. Em favor do caso. In: LOBATO, L. M. P. A semântica na linguística moderna: o léxico. Rio de Janeiro: Francisco Alves Editora, 1977. p. 277-365.

GARDIN, J. C. Document analysis and linguistic theory. Journal of Documentation, Bingley, v. 29, n. 2, p. 137-168, jun. 1973a.

GARDIN, J. C. Linguistique et documentation. Bullettino d' informazioni, Roma, v. 13, n. 2-3, p. 67-85, apr./set. 1973b. Disponível em:

https://riviste.aib.it/index.php/boll/issue/viewlssue/843/97. Acesso em: 1 maio 2019.

GARDIN, J. C. Procédures d'analyse sémantique dans les sciences humaines. In: POUILLON, J.; MARANDA, P. (orgs.). Échanges et communications: mélanges offerts à Claude LéviStrauss à l'occasion de son 60ème anniversaire. Paris: Mouton, 1970. p. 628-657.

GIL, A. C. Como elaborar projetos de pesquisa. 5. ed. São Paulo: Atlas, 2008.

GOMES, H. E.; CAMPOS, M. L. A. A organização do conhecimento na web: contribuições de Shiyali Ramamrita Ranganathan e Ingetraut Dahlberg. Niterói: IACS/UFF, 2019. (Grupo de pesquisa Estudos Ônticos e Ontológicos em Contextos Informacionais: representação, recuperação e métricas) (Cadernos Acadêmicos, n. 1).

GOMES, H. E.; MOTTA, D. F.; CAMPOS, M. L. A. Revisitando Ranganathan: a classificação na rede. Rio de Janeiro, ago. 2006. Disponível em:

http://www.conexaorio.com/biti/revisitando/revisitando.htm\#leis. Acesso em: 25 fev. 2019. 
HJØRLAND, B.; ALBRECHTSEN, H. Toward a New Horizon in Information Science: DomainAnalysis. Journal of the American Society for Information Science, Chapel Hill, v. 46, n. 6, p. 400-425, 1995.

HJØRLAND, B. Concept theory. Journal of the American Society for Information Science and Technology, Chapel Hill, v. 60, n. 8, p. 1519-1536, 2009.

HJøRLAND, B. Semantics and knowledge organization. Annual Review of Information Science and Technology, Silver Spring, v. 41, p. 367-405, 2007.

HJØRLAND, B. What is Knowledge Organization (KO)? Knowl. Org., Baden-Baden, v. 35, n. 2/3, p. 86-101, 2008.

INSTITUTO DE LINGUÍSTICA TEÓRICA E COMPUTACIONAL. Dicionário de termos linguísticos. [200-]. Disponível em:

http://www.portaldalinguaportuguesa.org/?action=terminology\&act=view\&id=2708. Acesso em: 16 maio 2020.

INTERNATIONAL STANDARD ORGANIZATION. ISO 25964: thesauri and interoperability with other vocabularies. Part 1: thesauri for information retrieval. Geneve: International Standard Organization, 2011.

JAPIASSU, H. Interdisciplinaridade e patologia do saber. Rio de Janeiro: Imago, 1976.

KAMIKAWACHI, D. Aspectos semânticos da definição terminológica (DT): descrição linguística e proposta de sistematização. 2009. 161 f. Dissertação (Mestrado em Linguística) - Centro de Educação e Ciências Humanas - Universidade Federal de São Carlos (UFSCar), São Carlos, 2009.

KOBASHI, N. Y. Análise documentária: considerações sobre um modelo lógico-semântico. In: CUNHA, I. M. R. F.; KOBASHI, N. Y.; AMARO, R. K. O. F. (Coord.). Análise documentária: considerações teóricas e experimentações. São Paulo: FEBAB, 1989. p. 45-57.

KOBASHI, N. Y. Fundamentos semânticos e pragmáticos da construção de instrumentos de representação de informação. DataGramaZero - Revista de Ciência da Informação, v. 8, n. 6, dez. 2007. Disponível em: https://www.brapci.inf.br/index.php/res/download/45259. Acesso em: 10 ago. 2018.

LOPES, E. Fundamentos da linguística contemporânea. São Paulo: Cultrix, 1976.

LOPES, E. Fundamentos da linguística contemporânea. 20. ed. São Paulo: Cultrix, 2008.

LYONS, J. Semântica. Lisboa: Martins Fontes, 1977. v. 1.

MACULAN, B. C. M. S. Estudo e aplicação de metodologia para reengenharia de tesauro: remodelagem do THESAGRO. 2015. 339 f. Tese (doutorado) - Universidade Federal de Minas 
Gerais, Escola de Ciência da Informação. Disponível em: http://hdl.handle.net/1843/BUBD9ZKMUV. Acesso em: 23 maio 2018.

MELO, M. A. F.; BRÄSCHER, M. Termo, conceito e relações conceituais: um estudo das propostas de Dahlberg e Hjørland. Ciência da Informação, Brasília, DF, v. 41, n. 1, p. 67-80, jan./abr. 2014. Disponível em: http://revista.ibict.br/ciinf/article/view/1419/1597. Acesso em: 9 abr. 2019.

POPPER, K. R. Conhecimento objetivo. Tradução de Milton Amado. Belo Horizonte: Editora Itatiaia, 1975.

POTTIER, B. A definição semântica nos dicionários. In: LOBATO, L. M. P. A semântica na linguística moderna: o léxico. Rio de Janeiro: Francisco Alves Editora, 1977. p. 21-31. POTTIER, B. Linguistique générale: théorie et description. Paris: Klincksieck, 1974.

RANGANTHAN, S. R. Colon Classification. Bombay: Ásia Publishing House, 1963.

RANGANATHAN, S. R. Prolegomena to library classification. 3. ed. New York: Asia Publishing House, 1967. Disponível em: https://repository.arizona.edu/handle/10150/106370. Acesso em: 27 fev. 2019.

ROTHER, E. T. Revisão sistemática X revisão narrativa. Acta Paul. Enferm., São Paulo, v. 20, n. 2, p. vii-viii (Editorial), jun. 2007. Disponível em:

http://www.scielo.br/scielo.php?script=sci arttext\&pid=S0103-

21002007000200001\&lng=en\&nrm=iso. Acesso em: 1 abr. 2020. DOI: 10.1590/S0103-

21002007000200001.

TAMBA-MECZ, I. A semântica. São Paulo: Parábola, 2006.

UNIVERSIDADE FEDERAL DE MINAS GERAIS (UFMG). Escola de Ciência da Informação. Departamento de Organização e Tratamento da Informação. Disciplina Linguagens de Indexação: ementa. Belo Horizonte, 2017. Disponível em: http://colgradbiblio.eci.ufmg.br/. Acesso em: 3 abr. 2020.

UNIVERSIDADE DE SÃO PAULO (USP). Faculdade de Filosofia, Ciências e Letras de Ribeirão Preto. Disciplina Linguagens documentárias: ementa. Ribeirão Preto, 2016. Disponível em: https://edisciplinas.usp.br/pluginfile.php/1815565/mod resource/content/1/Conte\%C3\%BAdo\%2OP rogram\%C3\%A1tico.pdf. Acesso em: 3 abr. 2020.

\section{AGRADECIMENTOS}

Agradecemos ao apoio recebido do Conselho Nacional de Desenvolvimento Científico e Tecnológico (CNPq) Processo: 303650/2019-2, à Pró-Reitoria de Pós-Graduação da UFMG e ao Programa de Pós-Graduação em Gestão \& Organização do Conhecimento (PPGGOC/ECI/UFMG). Agradecimento especial à Coordenadoria de Biblioteca e Gestão de Informação (CBGI) do Tribunal de Contas do Estado de Minas Gerais (TCEMG). 